\title{
Comprehensive geriatric assessment for older adults admitted to hospital: meta-analysis of randomised controlled trials
}

In this research paper by Graham Ellis and colleagues (BMJ 2011;343:d6553, doi:10.1136/bmj.d6553), the authors should have included the following acknowledgment of the Cochrane Collaboration: "This article is based on a Cochrane Review published in the Cochrane Database of Systematic Reviews (2011;7:doi:10.1002/14651858.CD006211.pub2) (see www. thecochranelibrary.com for information). Cochrane Reviews are regularly updated as new evidence emerges and in response to feedback, and the Cochrane Database of Systematic Reviews should be consulted for the most recent version of the review."

Cite this as: BMJ 2011;343:d7795

๑ BMJ Publishing Group Ltd 2011 